\title{
As contribuições de Seymour Fisher para os estudos em imagem corporal
}

\author{
Seymour Fisher contributions to research on body image
}

\author{
P.R.L. Ribeiro, M.C.F. Tavares
}

RESUMO

O objetivo deste artigo é apresentar de maneira sistematizada os conhecimentos produzidos por Fisher, durante seus trinta anos dedicados às pesquisas em imagem corporal. Foi realizada uma pesquisa bibliográfica, com procedimentos de coleta, análise e interpretação de dados. Quatro livros publicados por Fisher, que não são traduzidos para a língua portuguesa, foram consultados. Suas principais contribuições teóricas foram acerca da percepção corporal e de distorções da percepção corporal, das fronteiras corporais, da atribuição de significados a partes específicas do corpo e da consciência geral do corpo. O autor correlacionou estas dimensões da imagem corporal com mecanismos de defesa, processos adaptativos e ansiedade corporal, além de considerar o papel da personalidade e da cultura na interface destas relações. Seu intuito foi pormenorizar o complexo fenômeno da experiência corporal. Este estudo traz as importantes contribuições de Fisher para os estudos em imagem corporal, visando melhor difundir estes conhecimentos para o desenvolvimento das pesquisas em imagem corporal no Brasil.

Palavras-chave: Seymour Fisher, imagem corporal, fronteiras corporais, consciência corporal, percepção corporal

ABSTRACT

The aim of this work was to systematically review Seymour Fisher contributions to research on body image. A literature review of his work on body perception, distorted body image, body boundary, assigned meanings to specific body areas, and general body awareness was carried out on four of the books written by the author. Fisher correlated those variables with defense mechanisms, adaptation, and body anxiety. Moreover, he also considered the roles played by culture and personality on the complex phenomenon of body experience. This review intends to disseminate Seymour Fisher contributions among Brazilian researchers on body image.

Keywords: Seymour Fisher, body image, body boundary, body awareness, body perception

Submetido: 01.05.2010 | Aceite: 15.12.2010

Patrícia Russo Leite Ribeiro e Maria da Consolação Fernandes Tavares. Faculdade de Educação Física/UNICAMP, Campinas - SP, Brasil.

Endereço para correspondência: Patrícia Russo Leite Ribeiro, Rua Sete de Setembro, 4050, Vila Faria, CEP:13.569000 São Carlos/SP - Brasil.

E-mail: pirusso@uol.com.br 
$\mathrm{O}$ início do século XX foi marcado pelo grande interesse dos pesquisadores em compreender a estrutura cerebral, sua organização e funcionamento. Os neurologistas investigavam a natureza dos processos de organização da percepção corporal e as estruturas cerebrais responsáveis por manter um padrão adequado destas percepções. A partir daí, a ideia de uma imagem corporal ia ao encontro de tentativas clínicas para se compreender formas neuropatológicas de experiências corporais, incluindo fenômenos como o do membro fantasma e a anosognosia (Fisher, 1990). As pesquisas, na época, se direcionavam a investigar a relação entre percepções corporais distorcidas e danos cerebrais e/ou corporais, mas os aspectos psicológicos envolvidos nestas relações eram, ainda, negligenciados.

Alguns neurologistas se destacaram nestas pesquisas ao oferecerem novas formas de compreender tal fenômeno. $\mathrm{Na}$ primeira década do século XX, Henry Head propôs o termo esquema corporal, explicando que cada indivíduo constrói um modelo de si, que constitui um padrão no qual posturas e movimentos vão se compondo de maneira coerente com este padrão. Propôs a integralidade entre as diferentes percepções corporais e a influência de aspectos inconscientes nestas experiências. Nos anos 30, Schilder abordou a imagem corporal de forma sistêmica, considerando existir, além dos fatores neurológicos e fisiológicos, o papel fundamental dos aspectos psicológicos e socioculturais na construção da imagem corporal. Propôs que a imagem corporal é um fenômeno multifacetado, complexo, dinâmico e experienciado por todo e qualquer indivíduo. Para ele, a imagem corporal de um indivíduo é a figuração do seu corpo formada em sua mente, ou seja, é o modo pelo qual o corpo a ele se apresenta (Fisher, 1990).

Diante das novas descobertas da neurociência, inúmeras pesquisas por todo o mundo se empenhavam em estudar a imagem corporal em sua complexidade, porém a comunicação entre os pesquisadores era escassa, as pesquisas se encontravam isoladas e desarticuladas. Seymour Fisher, psicólogo interessado em fortalecer esta linha de pesquisa, se propôs, em seus trinta anos de carreira, a agrupar estes estudos, organizá-los e disponibilizá-los de forma sistematizada através da publicação de três livros de revisão de literatura, nos quais reúne mais de quatro mil referências e oferece formulações teóricas acerca da experiência corporal. A explicação razoável para uma relativa negligência em relação ao pioneirismo de Fisher é que seu trabalho foi ofuscado pela crescente predominância da abordagem cognitivocomportamental da imagem corporal, que acabou por obscurecer a perspectiva psicodinâmica com a qual o autor trabalhava (Cash \& Pruzinsky, 2002).

No Brasil, com exceção de "O orgasmo da mulher" (Fisher, 1973b), nenhum dos seus outros dezasseis livros foi traduzido para a língua portuguesa. Reconhecendo o importante papel de Fisher no meio científico internacional (Cash, 2004; Cash \& Pruzinsky, 2002), é fundamental, adequado e necessário para um avanço ainda maior das pesquisas brasileiras, que as ideias de Fisher sejam melhor difundidas entre os pesquisadores da imagem corporal no Brasil. Portanto, o objetivo deste trabalho é apresentar de maneira sistematizada os conhecimentos produzidos por este autor.

\section{DESENVOLVIMENTO}

Como metodologia de trabalho, foi realizada uma pesquisa do tipo bibliográfica, baseada nos rigores científicos propostos por Cervo e Bervian (1975), Salvador (1982) e Lakatos e Macconi (1991). As etapas da pesquisa envolveram coleta, análise e interpretação de dados, realizados através do levantamento bibliográfico e das leituras informativa e interpretativa, respectivamente. O levantamento bibliográfico permitiu identificar que Fisher publicou dezessete livros ao longo de sua carreira e, dentre eles, quatro (Fisher 1970, 1973a, 1986; Fisher \& 
Cleveland, 1968) tratavam especificamente da imagem corporal, sendo estes, então, o material que passou pelos processos de leitura para o presente estudo. Decidiu-se trabalhar com suas publicações em livros, em detrimento dos mais de duzentos artigos de sua autoria disponíveis em bases de dados digitais, uma vez que suas obras além de citar estes mesmos artigos, se organizam de uma forma que permite ao leitor ter um acesso amplo, detalhado e completo das formulações teóricas e práticas que Fisher propôs ao longo de sua carreira enquanto pesquisador.

Durante o levantamento bibliográfico, foi encontrado um artigo de Gale (2003) que trouxe maiores detalhes sobre a biografia de Seymour Fisher. Ele nasceu em 13 de maio de 1922 em Baltimore, MD e faleceu aos 74 anos, de infarte, em 5 de dezembro de 1996 em Manlius, NY. Filho de Sam e Jean Fisher, casou-se com a psicóloga Rhoda Lee Feinberg (1924-2004) em 22 de março de 1947, com quem teve dois filhos, Jerid Martin e Eve Phillis. Estudou psicologia na Universidade de Chicago, tornando-se Ph.D. em 1948. Trabalhou no Illions Neuropsychiatric Institute, em Chicago (1945-1948), no Elgin State Hospital (1949), no Houston's Veterans Administration Hospital (1952-1956) e no Baylor University College of Medicine (19571961). Em 1961, Fisher foi para a SUNY, State University of New York e trabalhou no Upstate Medical Center, em Syracuse, onde lecionou, dirigiu estudos e liderou a divisão de pesquisas em psicologia até o fim de sua vida (Gale, 2003). Suas dezassete publicações trataram de temas como drogas psicoativas, sexualidade feminina, teoria freudiana, psicologia do humor, psicologia infantil e uso de medicamentos, imagem corporal e comportamento (Freeman, 1996).

Em seu primeiro livro, publicado com Sidney Cleveland ("Body image and personality", 1968), os autores introduziram o referencial teórico no qual estavam se baseando para investigar o fenômeno da imagem corporal, ressaltando as proposições de Paul Schilder (Schilder, 1999) sobre o novo conceito de corpo formulado a partir da ideia de uma experiência psicológica, focada nas atitudes e sentimentos que cada indivíduo possui sobre seu próprio corpo. Este fenômeno, denominado imagem corporal, refere-se às experiências individuais subjetivas do corpo e à maneira como o indivíduo as organiza ao longo do seu desenvolvimento. Para Schilder, a maneira de o indivíduo lidar com a difícil tarefa de organizar as suas sensações corporais vem a ser uma das primeiras formas de organização de padrões individuais para a interpretação do mundo.

É baseado nesta perspectiva que os autores (Fisher \& Cleveland, 1968) revisam detalhadamente pesquisas e pensamentos prévios a respeito do fenômeno da imagem corporal, descrevem suas novas formulações teóricas e o programa de investigação que se desenvolveu destas formulações, buscando integrar os diversos achados em uma teoria que se referia à forma pela qual a imagem corporal atua no funcionamento da personalidade do indivíduo.

Depois da publicação deste livro, as pesquisas sobre o conceito de corpo enquanto um fenômeno psicológico cresceram significativamente, segundo o autor (Fisher, 1970). Porém, apesar de diversos estudos tentarem compreender como é que cada indivíduo aprende a integrar seus sentimentos sobre o corpo e como ele os relaciona com o que percebe ao seu redor, o domínio destes conhecimentos encontrava-se, ainda, rudimentar. Fisher publicou um novo livro ("Body experience in fantasy and behavior", 1970) que, através de uma revisão de artigos publicados entre 1958 e 1969, focou na investigação e compreensão da organização das experiências corporais, na forma como modos característicos de perceber seu corpo estão relacionados à personalidade e como isto influencia nos processos cognitivos e na construção da fantasia. Para Fisher (1970), a experiência corporal adquire um significado psicológico e este vai influenciar nas tomadas de decisão e no comportamento do indivíduo. 
O autor observava aspectos particulares da experiência corporal como estratégias para a manutenção de um corpo seguro, conforme descreveu em sua publicação de 1973 ("Body consciousness: you are what you feel").

Em sua última publicação, os dois volumes do "Development and structure of the body image" (1986), Fisher conseguiu agregar inúmeros conhecimentos sobre a imagem corporal, oferecendo ao meio científico formulações teóricas consistentes que servem de alicerce para pesquisas na área. A proposta de revisão literária do primeiro volume se baseou no fato de que desde sua publicação anterior de revisão sobre o tema (Fisher, 1970), muitos estudos e observações sobre imagem corporal e percepção corporal continuaram a se acumular, porém de forma bastante isolada, sendo relevante, então, revisá-los e assimilá-los dentro de um quadro teórico que pudesse fortalecer o desenvolvimento desta linha de pesquisa.

Fisher (1986) defendeu, assim como Schilder (1999), que a organização da imagem corporal é multidimensional. Num dado momento, o indivíduo pode estar monitorando diversos aspectos de seu corpo simultaneamente (posição no espaço, integri-dade dos limites corporais, mudanças no seu tamanho aparente etc), que podem ou não ser independentes um do outro.

O caráter multifacetado da imagem corporal implica na dificuldade em pesquisar este fenômeno. Esta problemática tão presente nas atuais pesquisas sobre o tema (Campana \& Tavares, 2009; Tavares, 2003) já era detectada pelo autor. Para Fisher (1986), não se pode agregar, por conveniência, alguns aspectos limitados da experiência corporal e afirmar que isto é a imagem corporal. Investigadores são surpreendidos quando aplicam diferentes medidas para avaliar a experiência corporal e nos resultados não encontram nenhuma correlação entre os dados. Isto não significa que a imagem corporal não é um conceito válido, mas sim que é tão multidimensionada que os modelos de pesquisas existentes não são capazes de avaliar tal complexidade como um todo, sendo necessário ter-se em mente que o objeto de estudo em questão trata-se de um recorte, de apenas um aspecto referente ao fenômeno imagem corporal.

O volume 2 da publicação de 1986 apresenta, de forma detalhada, as pesquisas preocupadas em testar e avaliar os principais conceitos teóricos relacionados à imagem corporal que Fisher desenvolveu. Tais conceitos se enquadram em quatro abrangentes tópicos: organização das fronteiras da imagem corporal, atribuição de significados a partes específicas do corpo, consciência geral do corpo e distorções na percepção corporal (Fisher, 1986). Segundo Shontz (1969), Fisher usou este volume para elaborar teoricamente e empiricamente dois postulados que apareceram em seus primeiros escritos: as fronteiras corporais e a distribuição diferencial de atenção às partes do corpo.

Apesar de muitos autores defenderem que é preciso ter cautela no emprego dos diferentes termos que se referem ao corpo (como imagem corporal, esquema corporal, conceito corporal, percepção corporal), Fisher parte do ponto de vista de que qualquer aspecto de qualquer experiência corporal está significativamente afetado pela personalidade, portanto todas as nomenclaturas que aparecem sobre o corpo se convergem em experiência corporal.

A partir de todo este referencial teórico tomado por Fisher, serão abordadas a seguir as três grandes dimensões da imagem corporal aprofundadas por ele durante a sua carreira: a percepção corporal, a fronteira corporal e a consciência corporal.

\section{A Percepção Corporal}

\section{Desenvolvimento da percepção corporal}

Sobre o desenvolvimento da percepção corporal, Fisher considerou as ideias de Piaget (1954) de que a criança começa a construir uma noção básica do mundo através das suas experiências sensório-motoras. Para Piaget, o corpo em ação, movimentando-se no espaço em busca de um objeto, oferece um padrão 
para a estruturação do mundo. Assim, as primeiras experiências são de caráter corporal e se organizam a partir da espacialidade do corpo. Piaget considerou que a ação do corpo é a matéria-prima para todas as adaptações intelectuais e perceptivas. Neste sentido, ao longo do seu desenvolvimento, a criança internaliza tais ações e esta internalização envolve a criação de imagens que representam as sequências sensório-motoras.

Para Fisher, Werner (1957) foi pioneiro ao atribuir importância ao corpo enquanto um construto psicológico. Ele sugeriu que as experiências corporais infantis são fundamentais para a construção do seu mundo e colorem as suas percepções deste mundo. Ele descreve como a percepção corporal oferece estrutura para a definição do eu e como a aquisição da linguagem e as habilidades cognitivas estão fortemente relacionadas à imagem corporal e às sensações corporais.

Segundo Fisher, Schilder (1999) foi o teórico da personalidade que atribuiu maior importância à imagem corporal no processo de desenvolvimento do ser humano. Para ele, a criança nasce sem a consciência de seu corpo, sem diferenciar este corpo dos demais objetos. O mundo e o corpo são experiências indissociáveis, em que uma não é possível sem a outra. Considerando que outras áreas do corpo, como os olhos e a pele, também são pontos de referência proeminentes, assim como as zonas erógenas, na construção das imagens que a criança cria sobre seu corpo.

Analisando estes e outros autores como Gellert (1962, 1975), Jourard e Secord (1955), Ayres (1961) e Long e Looft (1972), Fisher (1986) propôs que a criança vai se tornando cada vez mais conhecedora do seu território corporal. O mapa do seu corpo vai, gradualmente, ficando mais complexo e diferenciado, o que a torna capaz de aperfeiçoar a avaliação das propriedades físicas do seu corpo. A percepção corporal parece contribuir para um posterior domínio de habilidades cognitivas e para a consciência das regras culturais do meio em que vive. Os pais executam um importante papel no processo de diferenciação eu-mundo. A criança experiencia a estabilidade corporal, mas existe uma constante preocupação com possíveis "invasões" ao corpo que podem violar esta constância e desestabilizar a integridade da sua imagem corporal.

\section{Experiências de tamanho do corpo}

Grande parte dos estudos sobre o fenômeno da imagem corporal na segunda metade do século XX tinha como foco a análise do porquê das pessoas diferirem entre si quanto às percepções de quão grandes ou pequenas elas são. As variações quanto ao tamanho atribuído ao corpo ou à parte dele envolvem sentimentos que o indivíduo tem em relação a este corpo. A literatura clínica demonstrava inúmeros casos de experiências distorcidas de tamanho do corpo em pessoas diagnosticadas com esquizofrenia, anorexia nervosa, pessoas obesas ou que sofreram amputação (fenômeno do membro fantasma), danos cerebrais, ou, ainda, pessoas sob o efeito do consumo de substâncias psicoativas como o LSD (Fisher, 1970).

Sua última revisão, de 1986, apresentou de forma detalhada o trabalho de Shontz (1969), sobre os determinantes da percepção de tamanho do corpo. Fisher (1986) considera Shontz um grande pesquisador na área, uma vez que realizou uma série de estudos sobre a percepção do tamanho do corpo e desenvolveu modos de mensuração capazes de investigar, principalmente, a diferença entre o julgamento do tamanho do corpo e o julgamento do tamanho de objetos. Shontz (1969) analisou como diferentes condições de mensuração afetam tais julgamentos e quais as técnicas mais eficazes para a estimação do tamanho do corpo. Shontz forneceu, ainda, importantes contribuições para a literatura sobre a imagem corporal. Para Fisher, a sua maior contribuição foi demonstrar que os julgamentos do tamanho do corpo diferem dos julgamentos do tamanho do objeto, sendo relativamente menos acurados, mais variáveis e influenciados pela localização espacial das partes do corpo do indivíduo. 
Fisher analisou outros estudos, que traziam investigações acerca de diferentes variáveis influenciando na percepção normal do tamanho do corpo, verificando: (a) a influência que o movimento ativo de uma parte específica do corpo pode exercer sobre o julgamento do tamanho da mesma (Fuher \& Cowan, 1967; Hester, 1970; Rossi \& Zoccolotti, 1979); (b) a diferença no julgamento do tamanho de uma parte do corpo quando o indíviduo está em movimento ou parado (Hart, 1971; Stiles \& Smith, 1977); (c) a relação: quanto menos o indivíduo se percebe diferenciado de um determinado objeto, mais este objeto se revela "próximo" do seu "eu", isto é, possuindo um significado particular e subjetivo para aquele indivíduo (Schlater, Baker, \& Wapner, 1970); e (d) que a técnica sensori-tonic (Wapner, 1960) pôde demonstrar que variáveis como o contexto espacial (ambientes abertos ou fechados), a articulação das bordas (ser tocado ou não ser tocado) e a função (segurar ou não segurar um objeto ou ferramenta) também influenciam a estimação do tamanho de partes do corpo (Fisher, 1970). Fisher (1986) verificou que os dados demonstravam que quanto maior complexidade e similaridade com o corpo humano, menos o objeto é percebido de forma bem precisa. Esta relação de precisão agrava-se ainda mais quando este objeto é o corpo de outra pessoa.

A dificuldade em apurar as dimensões do corpo de maneira acurada pode ter algumas razões. Uma delas seria o aspecto psicológico e emocional envolvido na percepção do próprio corpo, que poderia influenciar de maneira errônea no julgamento correto do tamanho do corpo. A outra seria que a densidade com que a pessoa experiencia seu corpo favoreceria ambiguidade sobre suas reais dimensões. Fisher demonstrou que quando a pessoa se movimenta e adota novas posturas, as partes do seu corpo mudam de forma e magnitude. $\mathrm{O}$ corpo se apresenta como uma massa fluída que acaba por dificultar a definição correta do seu tamanho. Segundo o autor, até mesmo estruturas mais rígidas, como a cabeça e o antebraço, têm seu tamanho aparentemente modificado em comparação com quando a pessoa movimenta os músculos enquanto come, fala ou pega algum objeto, quando ganha ou perde peso, quando percebe mudança de temperatura ou quando sente os efeitos de tirar ou colocar roupas. A suposta pouca precisão na percepção do tamanho corporal pode, paradoxalmente, se reverter em formas bastante precisas quando a pessoa experiencia alterações crônicas no tamanho do seu corpo, ou seja, em situações que representam risco real para a integridade do seu corpo.

Outros dados trazidos por Fisher foram as formas seletivas da percepção corporal. Algumas áreas do corpo são tipicamente sobreestimadas enquanto outras subestimadas. Os fatores que influenciam estas formas seletivas de percepção podem ser psicológicos (satisfação ou insatisfação com o corpo), culturais, funcionais (decorrente, por exemplo, de uma deficiência) ou, ainda, a localização do corpo no espaço (a simples rotação do corpo para uma nova posição pode alterar a percepção do mesmo ou de parte dele). Os diferentes tamanhos atribuídos às partes do corpo também refletem qualidades e valores atribuídos a elas. Os setores do corpo diferem entre si quanto às proeminências corporais percebidas e cada setor está relacionado a valores e interesses específicos (Fisher, 1986). O julgamento exagerado (tanto para mais quanto para menos) pode, ainda, ser a expressão de uma reação defensiva contra mudanças corporais desagradáveis que quebram a estabilidade corporal e geram ansiedade.

Fisher concluiu que dois achados básicos, em particular, emergiram da literatura sobre distorções da percepção corporal: (1) os atributos de tamanho do corpo humano são experienciados como sendo distintos dos atributos de tamanho dos outros objetos do mundo; (2) os tamanhos atribuídos às áreas do corpo são influenciados por valores e intenções. Estes achados ajudaram a estabelecer que o espaço corporal possui propriedades perceptivas peculiares que, ao 
menos em parte, refletem a orientação psicológica do indivíduo.

\section{As Fronteiras Corporais}

Em 1968, Fisher e Cleveland propuseram o conceito de "body boundary". Nos dicionários de tradução da língua inglesa para a língua portuguesa, a palavra "boundary" pode ser traduzida para "limite" ou "fronteira". Optouse, aqui, pelo termo "fronteira" por considerar que este traduz melhor a ideia de uma permeabilidade ou penetrabilidade mais oscilante e flexível, em detrimento do termo "limite", que poderia dar a ideia de uma barreira mais rígida e fixa. Assim, o termo apresentado neste artigo é fronteiras corporais.

$\mathrm{O}$ conceito de fronteiras corporais foi elaborado e explorado detalhadamente no livro "Body image and personality" (Fisher \& Cleveland, 1968). A ideia de fronteira está ligada à ideia de proximidade e distância. Fronteiras são linhas de demarcação e separação que definem o acesso a algo. $O$ conceito de fronteiras corporais refere-se às diferentes maneiras como as pessoas atribuem "firmeza" e "definição" às suas bordas corporais. Existem pessoas que possuem alto nível de diferenciação dos objetos, são aquelas que percebem seu corpo claramente delimitado. Num outro extremo, existem pessoas que o percebem desprovido de demarcação ou de diferenciação dos objetos "de fora".

Segundo Fisher (1986), existem diferenças individuais no modo pelo qual um indivíduo distingue o espaço ocupado por seu corpo daquele ocupado por objetos à sua volta. O que se pode verificar, de um modo geral, são as diferenças existentes entre pessoas com fronteiras corporais bem definidas e pessoas com fronteiras corporais mais indefinidas. Estas diferenças relacionam-se a aspectos de personalidade, valores e estilo de vida.

A distinção entre o interior e o exterior do corpo é um fator básico para a compreensão do conceito das fronteiras corporais. A superfície corporal é o que separa o mundo interior do mundo que cerca o indivíduo. Para Fisher (1973a), o indivíduo está constantemente construindo a noção de um corpo individualizado e experienciando vivências que aumentam ou rompem a segurança de suas fronteiras corporais. Há nele uma busca constante por se perceber como uma entidade que está segura e protegida, afastando de si um sentimento de vulnerabilidade. Este sentimento está relacionado à possibilidade de que algo ameaçador externo a ele invada seu corpo ou de que conteúdos internos (como fantasias, sentimentos, pensamentos), que ele não quer compartilhar, escape de si para o mundo. A ideia de fronteira, portanto, parte da admissão da função de proteção atribuída à periferia do corpo (Fisher, 1986).

Para desenvolver estudos sobre as fronteiras corporais, os autores (Fisher \& Cleveland, 1968) desenvolveram um método objetivo de mensuração do grau do estado de definição que o indivíduo atribui às suas bordas corporais. Os autores verificaram que ao fazer um recorte do teste projetivo de Rorscharch, os dados que dali emergiam eram consistentes ao trazerem informações referentes aos conteúdos inconscientes que o indivíduo manifestava sobre as propriedades das suas bordas corporais. A partir de um intenso estudo sobre as respostas dadas por pacientes com artrite reumatóide e do que havia em comum entre elas, os autores criaram tabelas e categorizaram as respostas, que se consistiam nas imagens projetadas nas pranchas de Rorscharch que faziam referência a qualidades especiais das fronteiras ou periferias de objetos, em termos de firmeza, maciez, textura, coloração, entre outros. Notaram que as referências se enquadravam em duas classes de respostas que vieram a ser as bases para dois escores diferentes: o Barrier score, cujas respostas faziam referência a qualidades da estrutura, da matéria (substância) e da superfície das periferias do objeto e o Penetration score, cujas respostas faziam referência a aspectos negativos das periferias, ao serem enfatizadas a fraqueza, a falta de substância, a ausência e a penetrabilidade de pessoas e objetos. Em 
ambos os fatores, para cada resposta dada, atribui-se o valor 1 (um). A pontuação final é o valor total de respostas, somados separadamente um do outro. $O$ instrumento foi submetido à validação e todos os dados estão descritos em Fisher e Cleveland (1968) e Fisher, 1986). O Barrier score apresentou boa validade e confiabilidade, enquanto o Penetration score apresentou vulnerabilidades, portanto Fisher deu preferência para a aplicação do Barrier score, no qual altos índices de respostas indicavam bom estado de definição das bordas corporais, fronteiras corporais bem articuladas.

Durante toda sua carreira, Fisher utilizou este instrumento para a avaliação das fronteiras corporais, pôde correlacionar os seus dados com dados fornecidos por outros instrumentos e fazer relações com traços de personalidade e comportamento humano. Assim, Fisher pôde verificar aspectos particulares do funcionamento das fronteiras corporais, apresentados a seguir:

1. Aspectos sociais das fronteiras corporais: Fisher encontrou uma correlação entre fronteiras corporais e relação interpessoal. Fronteiras corporais bem definidas facilitam o processo de comunicação do indivíduo. Aqueles indivíduos cujas bordas são bem definidas buscam se envolver com outras pessoas, se comunicar e iniciar novos relacionamentos. No entanto, não se pode assumir que toda pessoa que possui fronteiras bem definidas sempre será próxima fisicamente de outros indivíduos, nem que terá uma ampla gama de interações sociais. Ela pode ser mais aberta a algumas pessoas e menos a outras. $\mathrm{O}$ funcionamento das fronteiras corporais é um fenômeno complexo e deve ser analisado de maneira multifacetada. Fisher (1986) afirmou que, entre outras facetas, as fronteiras corporais são mediadoras das relações sociais.

2. Aspectos da personalidade: As metas e preferências pessoais de cada indivíduo estão relacionadas à sua personalidade. Fisher propôs que a estruturação das fronteiras corporais pode refletir aspectos como a autodeterminação, a escolha vocacional, o investimento em atividades físicas e a expressão de valores através da escolha das roupas. Ou seja, existe uma relação entre o estado de definição das fronteiras corporais e certos padrões de interesse do indivíduo. A sensação de um corpo seguro experienciada por pessoas com uma fronteira corporal bem definida aumenta a probabilidade de escolherem atividades que requerem situações de novos confrontamentos e de potencial desafiador.

3. Condições de enfrentamento: pessoas cujas fronteiras da imagem corporal são bem articuladas (isto é, aquelas que apresentaram altos escores no Barrier) lidam melhor com situações ameaçadoras. Elas costumam manter-se mais equilibradas e enfrentam estas situações de forma mais efetiva, ou seja, alcançam melhores resultados perante uma situação de estresse. Para Fisher, isto acontece porque suas bordas tanto lhes oferecem um sentimento de proteção quanto representam para elas uma base segura de operações para responder aos estímulos externos. Os baixos índices no Barrier indicaram certa vulnerabilidade ao estresse e dificuldade em manter equilíbrio perante situações "perigosas".

4. Padrões somáticos de respostas: A distinção entre o interior e o exterior do corpo, ponto central do conceito de fronteira corporal, tem demonstrado ter uma analogia psicológica. A ideia básica original do Barrier score sugeria uma relação entre a natureza das imagens elaboradas pelo indivíduo e os locais de sua sintomatologia somática. Esta relação foi fundamental para se começar a explorar possíveis ligações entre as imagens do Barrier e padrões de experiências somáticas. A maioria dos estudos analisados por Fisher e que foram realizados até 1970 apresentou uma relação significativa entre o estado de definição das fronteiras corporais e a probabilidade dos sintomas aparecerem na pele e/ou nos músculos e aparecerem em órgãos internos, como o estômago e o intestino. A interpretação dos dados significou que o nível do estado de definição das bordas não representa uma 
função relacionada ao desconforto que está sendo experienciado entre os locais da superfície corporal e os locais internos, mas é responsável por desempenhar um papel causal no desenvolvimento de sensações internas ou externas.

Nota-se que existe uma considerável estabilidade das fronteiras corporais, mas isto exige um grande esforço por parte do indivíduo. Existem inúmeras estratégias usadas para garantir a integridade das bordas, como a atividade física, as vestimentas, as tatuagens e o autotoque, ou seja, o ato de tocar-se. Os autotoques parecem aumentar em situações de estresse nas quais existe a perda da diferenciação do eu (Fisher, 1973). Outra maneira de reparar as fronteiras refere-se à própria pessoa exaltar a sua importância e centralidade. Cada indivíduo desenvolve as suas próprias estratégias somáticas e expressivas para a manutenção da sua fronteira corporal.

Fisher concluiu que enquanto cada indivíduo desenvolve um modo particular de experienciar suas fronteiras corporais, as formas de buscar tais experiências é flutuante e depende de fatores internos e externos ao sujeito. Os eventos cotidianos provavelmente alteram a noção de um limite corporal seguro e existe, nos indivíduos, uma busca constante para se manter estas fronteiras na sua integridade. $\mathrm{Na}$ inevitável inter-relação do indivíduo com o ambiente ao seu redor, a sua superfície corporal torna-se mediadora entre os dois mundos, o interno e o externo. Assim, as fronteiras corporais representam aquilo que o indivíduo permite ou não "permear" pela imagem corporal.

Segundo Fisher, as fronteiras corporais the oferecem a noção de um corpo seguro, protegido e menos vulnerável. Elas atuam como um mecanismo de defesa contra forças internas e externas que o indivíduo percebe como inaceitáveis, ameaçadoras ou perigosas e que podem colocar em risco a integridade da sua imagem corporal.

\section{A Consciência Corporal}

1. Atribuição de significados a partes específicas do corpo: Sistema de sinais

Fisher (1970) aprofundou o conceito de consciência corporal baseado em dados empíricos que davam suporte para considerar este processo um aspecto crucial para a organização da imagem corporal. Tal processo refere-se a como o indivíduo presta atenção às partes que considera mais importantes no seu corpo. Segundo o autor, o nível de atenção às várias partes do corpo está intimamente ligado à personalidade. Investigar como uma pessoa distribui atenção às diferentes partes do corpo seria um modo objetivo e confiável de se mensurar o nível de consciência destas regiões.

O instrumento desenvolvido pelo autor para avaliar como as pessoas distribuem a sua atenção às várias regiões do seu corpo foi denominado Body Focus Questionnaire (BFQ) (Fisher, 1970). O formato básico do instrumento apresenta ao sujeito uma série de referências verbais de regiões do corpo, pareadas, para que ele indique qual de cada par encontra-se de maneira mais clara em sua consciência naquele momento. O BFQ procura trazer dados quantitativos dos conteúdos subjetivos inerentes às experiências corporais de cada indivíduo. Após inúmeras investigações utilizando o BFQ e a análise minuciosa dos resultados obtidos, Fisher (1970) concluiu que o nível de consciência de uma área do corpo não é um fenômeno em si, mas sim uma função importante de defesa.

A relativa "nitidez" das várias regiões do corpo no esquema corporal serve como um sistema de organização que tem o papel de regular respostas. Assim, o indivíduo desenvolve uma série de dispositivos que vêm a ser fontes de sinais que modificam julgamentos e respostas. Foi demonstrado que a proeminência de algumas regiões corporais em especial afeta as atitudes do indivíduo e se dá de uma forma congruente com a teoria de que, em certo nível, a imagem corporal inclui uma rede periférica de sinais cujos propósitos são de defesa e adaptação. Estes sinais fornecem 
informações que vão sugerir se determinado estímulo deve ser evitado ou não, em função do seu potencial para desencadear ansiedade.

Os dados acumulados sobre as regiões marcantes do corpo visualizaram a complexidade deste sistema operacional. A proeminência perceptiva das áreas corporais se altera em função dos estímulos recebidos. Esta alteração afeta as respostas seletivas para estes estímulos. Informações são trocadas entre localidades centrais e periféricas. Fisher (1986), tendo em vista o padrão dos achados de pesquisas com o BFQ teorizou que a rede de sinais corporais fornece, constantemente, uma estrutura somática de julgamento para monitorizar e avaliar o estímulo com o qual o indivíduo se depara. Ou seja, os estímulos são filtrados através de uma matriz de experiências que eles desencadearam nas diversas localidades marcantes do corpo.

\section{Consciência geral do corpo: Proeminências corporais}

Autores como Duval e Wicklund (1972) se interessaram em investigar a consciência corporal enquanto mediadora do comportamento. A consciência corporal está envolvida em vários fenómenos como a culpa, a emoção, a memória, entre outros. A proeminência perceptiva do próprio corpo apareceu como um poderoso fator psicológico. Verificou-se que existem diferenças marcantes no modo pelo qual as pessoas são conscientes de seu corpo. Algumas delas são mais focadas nas sensações corporais enquanto outras parecem minimizar a percepção do que acontece no seu espaço corporal.

Fisher (1970) desenvolveu o Body Prominence Score - BPS, instrumento cujo objetivo era avaliar a consciência do corpo como um todo. O procedimento para se obter os escores é pedir para que o participante liste numa folha de papel "vinte coisas que você está atento a ou consciente de, exatamente agora". Ele também é solicitado a usar mais algumas palavras em cada uma das suas descrições. No protocolo obtido, todas as referências diretas ou indiretas a seu corpo são registradas.

A validação original do instrumento permitiu achados significativos (Fisher, 1970) e indicaram que pessoas com escores elevados estavam propensas a serem sensíveis às sensações corporais e manifestaram maior número de palavras com conotações corporais recordadas. Observou-se que o aumento do escore do BPS estava associado a algumas condições como, por exemplo, a espera por uma cirurgia, a experiência de um exame ginecológico e a atividade física.

A Tabela 1 apresenta um esquema que sintetiza as formulações teóricas de Fisher acima descritas. Estas formulações teóricas acerca da percepção corporal, das fronteiras corporais e da consciência corporal dizem respeito às dimensões $\mathrm{e}$ às formas de organização e funcionamento da imagem corporal, compreendida enquanto um fenômeno complexo, multidimensional e singular experienciado por todo e qualquer ser humano. Fisher considerou que a personalidade, o ajustamento psicológico, as relações interpessoais e os aspectos fisiológicos do indivíduo constituem a imagem corporal vindo esta última a influenciar o seu comportamento. Numa relação de retroalimentação, o comportamento e a história de vida também acabam por modelar a imagem corporal do indivíduo.

\section{CONCLUSÕES}

A importância de Seymour Fisher deve-se, antes de outra coisa, ao fato de ter sido o primeiro psicólogo psicanalista a estudar profundamente a imagem corporal, tema que vinha sendo campo de estudo dos neurologistas da época. Assim, deu maior valor aos aspectos da personalidade que constituem o fenômeno. Desta forma, a maneira pela qual conduziu suas pesquisas teve um caráter singular. A partir de testes projetivos, cuja característica é a subjetividade, Fisher desenvolveu escalas de avaliação capazes de oferecer dados quantitativos para as investi- 
Tabela 1

Organização e funcionamento das dimensões que constituem a imagem corporal

\begin{tabular}{|c|c|c|c|}
\hline \multicolumn{4}{|c|}{ Imagem Corporal } \\
\hline Dimensões & Organização & Funcionamento & Finalidades \\
\hline \multirow[b]{2}{*}{$\begin{array}{l}\text { Percepção } \\
\text { corporal }\end{array}$} & Desenvolvimento & $\begin{array}{l}\text { Diferenciação eu-mundo; aquisição } \\
\text { gradual de habilidades. }\end{array}$ & \multirow[t]{2}{*}{$\begin{array}{l}\text { Manutenção do } \\
\text { corpo seguro }\end{array}$} \\
\hline & Distorções & $\begin{array}{l}\text { Super/subestimação no julgamento do } \\
\text { tamanho do corpo; atributos de } \\
\text { tamanho do corpo versus de objetos. }\end{array}$ & \\
\hline \multirow{4}{*}{$\begin{array}{l}\text { Fronteiras } \\
\text { corporais }\end{array}$} & Aspectos sociais & $\begin{array}{l}\text { Mediador de relações sociais; } \\
\text { comunicação e intimidade. }\end{array}$ & \multirow{2}{*}{$\begin{array}{l}\text { - mecanismos } \\
\text { psíquicos de defesa e } \\
\text { proteção }\end{array}$} \\
\hline & Personalidade & Preferências, interesses individuais. & \\
\hline & Enfrentamento & $\begin{array}{c}\text { Ansiedade corporal perante estresse, } \\
\text { ameaça, perigo. }\end{array}$ & \multirow{2}{*}{$\begin{array}{l}\text { - regulação da } \\
\text { ansiedade corporal }\end{array}$} \\
\hline & $\begin{array}{l}\text { Padrões somáticos de } \\
\text { respostas }\end{array}$ & $\begin{array}{c}\text { Manifestação de sensações internas } \\
\text { versus externas. }\end{array}$ & \\
\hline \multirow{2}{*}{$\begin{array}{l}\text { Consciência } \\
\text { corporal }\end{array}$} & $\begin{array}{c}\text { Atribuição de } \\
\text { significados a partes do } \\
\text { corpo }\end{array}$ & $\begin{array}{c}\text { Matriz de sinais periféricos; } \\
\text { distribuição de atenção a diferentes } \\
\text { partes do corpo. }\end{array}$ & \multirow{2}{*}{$\begin{array}{l}\text { - condições de } \\
\text { enfrentamento }\end{array}$} \\
\hline & $\begin{array}{l}\text { Consciência geral do } \\
\text { corpo }\end{array}$ & $\begin{array}{l}\text { Proeminências corporais; atenção às } \\
\text { sensações corporais. }\end{array}$ & \\
\hline
\end{tabular}

gações. Seu intuito não era generalizar os traços de personalidade, mas sim encontrar aqueles que eram comuns dentro de uma população específica, o que poderia auxiliar nas intervenções profissionais requeridas por esta população, porém, sem deixar de lado a singularidade de cada indivíduo. Para o autor, as pesquisas em imagem corporal facilitam a compreensão de fatos comuns na nossa sociedade, como a busca crescente por tratamentos médicos e cirúrgicos, o processo de adaptação a deficiências e os distúrbios de comportamento.

Fisher foi responsável por agrupar as pesquisas sobre imagem corporal, que estavam sendo realizadas de maneira isolada por pesquisadores de todo o mundo e, desta forma, contribuiu historicamente para o desenvolvimento desta linha de pesquisa e sua legitimação dentro do meio científico. Ofereceu aos pesquisadores o novo conceito de fronteiras corporais, permitindo-lhes uma nova forma de compreensão da organização da imagem corporal. Ampliou seus estudos para diversas direções, fornecendo conteúdos importantes sobre drogas e placebos, psicologia infantil, psicanálise freudiana, sexualidade, entre outros, buscando sempre manter como pano de fundo a experiência corporal. Antecipou discussões tão atuais acerca de mídia, cultura, padrão de beleza, pressão social, aparência física e saúde. Pesquisou diversos aspectos da imagem corporal, que vinham sendo ocultados pelo interesse nos estudos sobre transtornos alimentares. Como resultado disso tudo, publicou, ao longo de trinta anos de carreira, dezassete livros e mais de duzentos artigos científicos com temas variados.

Para Fisher, o corpo representa o único lugar seguro que o indivíduo possui, o corpo é o invólucro do eu e é a base segura para as operações de interação entre os mundos interno e externo. O funcionamento da imagem corporal baseia-se na estabilidade de um eixo central, cuja função é fornecer um "mapa" do 
"eu", uma "armadura" que garante a noção contínua de uma identidade corporal e na dinamicidade, que possibilita uma contínua reconstrução para adaptações às mudanças corporais ao longo da vida e para transformações que permitem ao sujeito re-significar suas experiências. Fisher buscou em suas pesquisas compreender de que forma a imagem corporal interfere no comportamento humano e como o comportamento e as experiências corporais modelam a imagem corporal do indivíduo. Tratou, especialmente, das dimensões percepção corporal, fronteiras corporais e consciência corporal e as correlacionou com processos de adaptação, satisfação/ insatisfação com o próprio corpo, ansiedade corporal e mecanismos de defesa, ao mesmo tempo em que considerou $o$ papel da personalidade e da cultura na interface destas relações. Em sua obra, detalhou de forma pormenorizada o complexo fenômeno da experiência corporal.

Trazer os conhecimentos produzidos por Fisher para o Brasil permite proporcionar aos pesquisadores da área uma noção histórica dos caminhos percorridos pelas pesquisas em imagem corporal ao longo da segunda metade do século XX. Ele mesmo também direcionou inúmeras pesquisas a fim de aprofundar $\mathrm{o}$ conceito de imagem corporal e suas diferentes dimensões. Nestas pesquisas, participaram diferentes populações e Fisher não se restringiu apenas a temas relacionados à patologia. Seus conhecimentos ajudaram a compreender a fundamentação conceitual da imagem corporal e compreender profundamente o conceito de imagem corporal é requisito para compreender o seu desenvolvimento, as possíveis formas de avaliação, as suas disfunções e possibilidades de mudanças.

Espera-se que os conteúdos aqui apresentados sirvam de referência para uma ampla gama de estudos e intervenções de diferentes profissionais que acreditam que o viés da imagem corporal possa ser uma alternativa eficaz para sua atuação.

\section{REFERÊNCIAS}

Ayres, A. J. (1961). Development of the body scheme in children. American Journal of Occupational Therapy, 15, 99-102.

Campana, A. N., \& Tavares, M. C. G. (2009). Avaliação da imagem corporal: Instrumentos $e$ diretrizes para pesquisa. São Paulo: Phorte.

Cash, T. F. (2004). Body image: Past, present and future. Body Image, 1, 1-5.

Cash, T., \& Pruzinsky, T. (Eds.). (2002). Body image: $A$ handbook of theory, research and clinical practice. New York: Guilford Press.

Cervo, A. L., \& Bervian, P. A. (1975). Metodologia científica para uso dos estudantes. São Paulo: McGraw-Hill.

Duval, S., \& Wicklund, R. A. (1972). A theory of objective self awareness. New York: Academic Press.

Fisher, S. (1970). Body experience in fantasy and behavior. New York: Appleton-Century-Crofts.

Fisher, S. (1973a). Body consciousness: You are what you feel. New Jersey: Prentice-Hall.

Fisher, S. (1973b). The female orgasm: Psychology, physiology, fantasy. New York: Basic Book.

Fisher, S. (1986). Development and structure of the body image. New Jersey: LEA.

Fisher, S. (1990). The evolution of psychological concepts about the body. In T. Cash \& $\mathrm{T}$. Pruzinsky (Eds.), Body images: Development, deviance and change (pp. 3-20). New York: The Guilford Press.

Fisher, S., \& Cleveland, S. (1968). Body image and personality ( $2^{\text {nd }}$ ed.). New York: Dover Publications.

Freeman, K. (1996, Dezembro). Seymour Fisher, 74: Studied Drugs and Sexuality. New York Times, New York. Consultado em 11 de Abril de 2008 a partir de http://www.nytimes.com/1996/ 12/15/nyregion/seymour-fisher-74-studieddrugs-and-sexuality.html

Fuher, M. G., \& Cowan, C. O. (1967). Influence of active movements, illumination, and sex on estimates of body-parts size. Perceptual and Motor Skills, 24, 979-985.

Gale, T. (2003). Biography - Fisher, Seymour (19221996): An article from Contemporary Authors. Michigan: Autor.

Gellert, E. (1962). Children's conception of the content and functions of the human body. Genetic Psychology Monographs, 65, 293-405.

Gellert, E. (1975). Children's constructions of their self-images. Perceptual and Motor Skills, 40, 307324. 
Hart, B. (1971). Size estimation as a measure of body image of the movement performer. Research Quarterly, 42, 391-394.

Hester, G. A. (1970). Effects of active movement on body-part size estimates. Perceptual and Motor Skills, 3, 607-613.

Jourard, S. M., \& Secord, P. F. (1955). Body-cathexis and the ideal female figure. Journal of Abnormal and Social Psychology, 20, 243-246.

Lakatos, E. A., \& Macconi, M. A. (1991). Fundamentos de metodologia científica. São Paulo: Atlas.

Long, A. B., \& Looft, W. R. (1972). Development of directionality in children: Ages six through twelve. Developmental Psychology, 6, 375-380.

Piaget, J. (1954). The construction of reality in the children. New York: Basic Books.

Rossi, B., \& Zoccolotti, P. (1979). Body perception in athletes and non-athletes. Perceptual and Motor Skills, 49, 723-726.

Salvador, A. D. (1982). Métodos e técnicas de pesquisa bibliográfica: Elaboração de trabalhos científicos. Porto Alegre: Sulina.
Schilder, P. (1999). A imagem do corpo: As energias construtivas da psique. São Paulo: Martins Fontes.

Schlater, J. A., Baker, A. H., \& Wapner, S. (1970). Changes in body perception during repeated trials. Research Princeton, NJ: Memorandum, Educational Testing Service.

Shontz, F. C. (1969). Perceptual and cognitive aspects of body experience. New York: Academic Press.

Stiles, D. B., \& Smith, H. M. (1977). A film technique for assessing children's selfestimation of body size under static and dynamic conditions. Perceptual and Motors Skills, 45, 1275-1282.

Tavares, M. C. G. (2003). Imagem corporal: Conceito e desenvolvimento. Barueri: Manole.

Wapner, S. (1960). An experimental and theoretical approach to body image. Comunicação apresentada no XVI International Congress of Psychology Bonn, Alemanha.

Werner, H. (1957). Comparative psychology of mental development. New York: International Universities Press.

(c) EY-No Todo o conteúdo da revista Motricidade está licenciado sob a Creative Commons, excepto quando especificado em contrário e nos conteúdos retirados de outras fontes bibliográficas. 